J. Lake Sci. (湖泊科学), 2019, 31(2): 482-492

DOI 10. 18307/2019. 0217

(C) 2019 by Journal of Lake Sciences

\title{
黄河伊洛河中下游鱼类多样性及群落结构”
}

\author{
林鹏程 ${ }^{1,2}$, 李淑贞 ${ }^{3}$, 秦祥朝 ${ }^{4}$, 程卫 ${ }^{5}$, 刘焕章 ${ }^{1,2 * *}$ \\ ( 1 : 中国科学院水生生物研究所,武汉 430072) \\ (2:中国科学院水生生物多样性与保护重点实验室,武汉 430072) \\ (3: 黄河流域水资源保护局,郑州 450004) \\ ( 4 : 黄河流域水环境监测中心, 郑州 450004) \\ (5:河南省洛阳水文水资源勘测局, 洛阳 471000)
}

摘 要: 为了解伊洛河中下游鱼类多样性、群落结构及其与环境因子的关系, 于 2016 年 2-12 月对伊洛河中下游 5 个河 段开展鱼类多样性及环境调查. 共采集鱼类 12361 尾,43 种, 隶属于 4 目 9 科 37 属. 伊洛河中下游鱼类群落的 ShannonWiener 多样性指数、Margalef 丰富度指数、Pielou 均匀度指数和 Simpson 指数变化范围分别为 $1.75 \sim 2.38 、 2.44 \sim 3.63 、 0.59 \sim$ 0.76 和 $0.73 \sim 0.86$. 各指数均以西草甸河段最高. 各河段优势种以粲 (Hemiculter leucisculus)、似鳊 (Pseudobrama simoni)、鲫 (Carassius auratus)、兴凯鱊(Acheilognathus chankaensis) 和鳑鲏属(Rhodeus) 等小型或广适性鱼类为主. 丰度/生物量比较 $(\mathrm{ABC})$ 曲线显示,除西草甸河段外,各河段优势鱼类群落均受到不同程度的干扰. 其中七里铺和黑石关鱼类群落处于严 重干扰状态, 以小型鱼类或大型鱼类的幼鱼为主. 采用圥余分析方法分析了鱼类群落结构与环境因子的关系, 发现除了 河床、水流、捕捞等因子以外, 氨氮、总磷浓度与 $\mathrm{pH}$ 是导致伊洛河中下游鱼类群落结构差异的主要影响因子. 针对伊洛河 鱼类多样性现状, 建议加强流域水质监管, 恢复河流连通性, 推进保护区全面禁渔, 开展生态修复等以恢复伊洛河河流 健康.

关键词 : 黄河 ; 中下游伊洛河 ; 多样性格局; 鱼类群落;圥余分析; 河流健康

\section{Pattern of fish diversity and assemblage structure in the middle and lower reaches of the Yiluo River, Yellow River}

\author{
LIN Pengcheng ${ }^{1,2}$, LI Shuzhen ${ }^{3}$, QIN Xiangchao ${ }^{4}$, CHENG Weixi ${ }^{5}$ \& LIU Huanzhang ${ }^{1,2 * *}$ \\ ( 1: Institute of Hydrobiology, Chinese Academy of Sciences, Wuhan 430072, P.R.China) \\ (2: Key Laboratory of Aquatic Biodiversity and Conservation, Chinese Academy of Sciences, Wuhan 430072, P.R.China) \\ (3: Yellow River Basin Water Resources Protection Bureau, Zhengzhou 450004, P.R. China) \\ (4: Yellow River Basin Water Environmental Monitoring Center, Zhengzhou 450004, P.R. China) \\ (5: Luoyang Hydrology and Water Resource Survey Bureau, Luoyang 471000, P.R.China)
}

Abstract: To understand the fish diversity and assemblage structure in the middle and lower reaches of the Yiluo River and to as-
sess the impacts of human activities on river ecosystems, six fish sampling occasions in five sites were conducted bimonthly in 2016 .
A total of 12361 individual fishes were collected in the river stretches, comprising 43 species belonging to 4 orders, 9 families and
37 genera. The Cyprinidae family, representing 28 taxa, accounted for $65.1 \%$ of the total number of fish species collected. Shan-
non-Wiener diversity index, Margalef species richness index, Pielou evenness index and Simpson's diversity index of fish communi-
ty in the investigation regions ranged from 1.75 to 2.38 , from 2.44 to 3.63 , from 0.59 to 0.76 and from 0.73 to 0.86 , respectively.
Fish species diversity in Xicaodian reach was highest among the five reaches. Abundance-Biomass Comparison ( ABC) Curve
showed that all sampling sites were subject to varying degrees of interference apart from Xicaodian reach. Fish communities in Qil-
ipu reach and Heishiguan reach were subject to the maximum interference with the dominant fish species were mainly small-sized

* 国家重点基础研究发展计划 (2017YFC0404401) 和伊洛河试点河段水生生物监测与评价项目联合资助. 2018-0626 收稿; 2018-08-22 收修改稿. 林鹏程 (1985 ), 男, 博士, 助理研究员;E-mail: linpc@ ihb.ac.cn.

** 通信作者; E-mail:hzliu@ihb.ac.cn. 
fish or young individuals of large-sized fish. Redundancy analysis was used to describe the relationship between the assemblage structures and associated environmental factors. Ammonia nitrogen, total phosphorus and pH accounted for the largest amount of variance. In view of the status of fish species diversity in the middle and lower reaches of the Yiluo River, it was suggested that managers should take steps, such as strengthening water quality management, restoring river connectivity, fishing banning in the reserves and conducting habitat restoration, to ensure the ecological protection and river health.

Keywords: Yellow River; middle and lower reaches of the Yiluo River; biodiversity pattern; fish assemblage; RDA; river health

淡水生态系统在人类社会中扮演着非常重要的角色, 它向人类提供了极其丰富的生物多样性和不可替 代的生态服务功能, 如饮用水、水产品等 ${ }^{[1]}$. 随着人口增长、社会经济的快速发展以及对生物资源不合理的 开发利用,河流、湖泊等自然水域生态系统出现了生物多样性下降、生态服务功能退化等问题 ${ }^{[2]}$. 鱼类是河 流生态系统健康重要的指示生物, 了解鱼类多样性和群落结构特征, 识别鱼类多样性变化的驱动因子有助 于河流生态系统的科学管理和保护 ${ }^{[3-4]}$.

伊洛河是黄河三门峡大坝以下最大的支流, 地处秦岭、伏牛山、崤山及黄土高原、洛阳盆地的衔接地带, 属暖温带向北亚热带的过渡区域, 流域内生境类型复杂多样, 生物多样性丰富 ${ }^{[5]}$. 洛河的鲤 (Cyprinus carpio haematoperus)、伊河的团头鲂 (Megalobrama amblycephala) 是当地历史上著名的经济鱼类,伊洛河进人黄河的 人口也是黄河中下游鱼类集中的产卵场之一 ${ }^{[6]}$. 但近年来, 随着流域内水土流失、钿、铇、金等有色金属和 煤、铝矾土、耐火黏土等矿产资源的无序开发利用、河段水电开发程度高、控水工程密集、农村工业盲目发展 等带来的环境问题, 伊洛河出现了湿地面积萎缩、水环境污染、河流连通性丧失等问题, 伊洛河鱼类资源及 多样性衰退严重 ${ }^{[7-10]}$.

然而, 目前有关伊洛河鱼类资源及其多样性的研究资料監乏, 制约了伊洛河流域生物多样性保护与生 态修复工作. 在此背景下,基于 2016 年 6 次鱼类多样性监测结果, 本研究分析伊洛河中下游鱼类多样性现 状, 探讨鱼类群落与环境因子的关系, 以期为伊洛河流域鱼类多样性保护和河流健康发展对策的制定提供 参考.

\section{1 材料与方法}

\section{1 研究区域概况}

伊洛河 $\left(33^{\circ} 33^{\prime} \sim 35^{\circ} 05^{\prime} \mathrm{N}, 109^{\circ} 45^{\prime} \sim 113^{\circ} 06^{\prime} \mathrm{E}\right)$ 是黄河的十大支流之一. 伊洛河流域多年平均水资源总 量 32.31 亿 $\mathrm{m}^{3}$, 平均含沙量 $4.4 \mathrm{~kg} / \mathrm{m}^{3}$. 伊洛河主要由伊河、洛河两大水系组成, 其中洛河发源于秦岭的华山 南麓洛南县, 全长 $410 \mathrm{~km}$, 流域面积 $12852 \mathrm{~km}^{2}$; 伊河发源于秦岭东支熊耳山区栾川县张家村, 在偃师市東庄 注人洛河, 全长 $268 \mathrm{~km}$, 流域面积 $6029 \mathrm{~km}^{2}$.

两河汇流后东流至巩义市洛口以北入黄河. 伊洛河流域涉及 2 个省、14 个县市, 地势总体上西南高、东 北低, 海拔最高超过 $2000 \mathrm{~m}$, 最低不到 $100 \mathrm{~m}$. 流域内地貌类型多样, 可划分为山地、丘陵和平原 3 种地貌单 元, 分别占全流域面积的 $52.4 \% 、 39.7 \%$ 和 7.9\%, 素有 “五山四陵一平川”之称. 伊洛河中下游以丘陵和平原 为主, 下游地区也是流域的经济重心所在, 有经济比较发达的重工业城市洛阳市、煤炭城市义马市和农村工 业实力强大的㫦师市和巩义市, 人口密度高, 土地承载力大 ${ }^{[9-10]}$.

为真实反映伊洛河河流鱼类的多样性现状, 采样河段尽量远离橡胶坝蓄水区, 以保证调查水域具有相 对自然的河流环境. 经前期实地踏勘, 本研究设置洛河凌波大桥 $\left(4^{*}\right)$ 、白马寺 $\left(3^{\#}\right)$ 河段, 伊河西草甸 $\left(5^{\#}\right)$ 河 段以及两河汇合后的黑石关 $\left(2^{\#}\right)$ 和人黄口七里铺 $\left(1^{\#}\right)$ 河段 5 个采样点 (图 1$)$.

\section{2 样品采集与环境调查}

采用自捕和渔民捕捞的方式对伊洛河中下游鱼类资源进行调查,调查时间为 2016 年 $2 、 4 、 6 、 8 、 10$ 和 12 月. 调查网具包括地笼、刺网等. 每个河段浮性定置刺网 3 个, 网目大小分别为 $2 、 6$ 和 $10 \mathrm{~cm}$, 网高 $1 \mathrm{~m}$, 每网 定置时间为 $24 \mathrm{~h}$; 虾笼 3 个, 网目为 $1 \mathrm{~cm}$, 长 $3 \mathrm{~m}$. 每次调查期间, 网具布设尽量涵盖不同类型的生境, 每个采 样点每次持续捕捞 $2 \mathrm{~d}$. 全年累计调查时间 40 天, 统计渔获物 71 船次. 调查期间, 采集鱼类现场鉴定种类, 进行全长、体长、体重等生物学测量. 现场未能鉴定的种类, 采用 $10 \%$ 福尔马林溶液固定, 带回室内依据《中 国淡水鱼类检索》、《中国动物志》、《黄河鱼类志》等相关文献进行鉴定 ${ }^{[1-14]}$. 在渔获物调查的同时, 测量相 


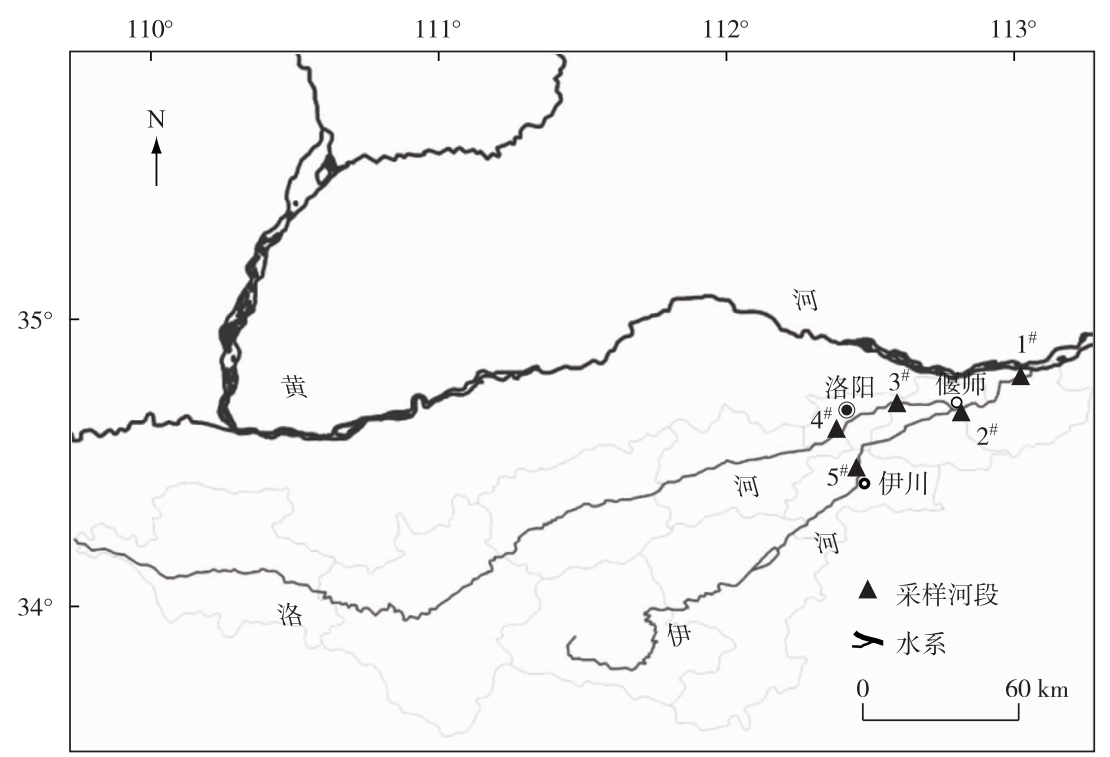

图 1 伊洛河中下游鱼类采样示意

Fig.1 Location of fish sampling sites in the middle and lower reaches of the Yiluo River

关的环境指标. 其中水温、 $\mathrm{pH}$ 值和电导率使用便携式水质分析仪 (YSI Professional Plus) 测定. 同时现场采集 $2 \mathrm{~L}$ 水样, 在实验室内测定总磷 $(\mathrm{TP})$ 、氨氮 $\left(\mathrm{NH}_{3}-\mathrm{N}\right)$ 、高锰酸盐指数 $\left(\mathrm{COD}_{\mathrm{Mn}}\right)$ 和五日生化需氧量 $\left(\mathrm{BOD}_{5}\right)$. 水 样采集、保存和室内测定参照《水和废水监测分析方法》 ${ }^{[15]}$.

\section{3 数据分析}

1.3.1 物种多样性指数 采用 Margalef 种类丰富度指数 $\left(D_{\mathrm{m}}\right) 、$ Shannon-Wiener 多样性指数 $\left(H^{\prime}\right) 、$ Pielou 均匀 度指数 $\left(J^{\prime}\right) 、$ Simpson 指数 $\left(D_{\mathrm{s}}\right)$ 分析鱼类群落多样性 ${ }^{[16-17]}$, 计算公式分别为:

$$
\begin{gathered}
D_{\mathrm{m}}=(S-1) / \ln N \\
H^{\prime}=-\sum_{i=1}^{S} P_{i} \cdot \ln P_{i} \\
J^{\prime}=H^{\prime} / \ln S \\
D_{\mathrm{s}}=1-\sum_{i=1}^{S} P_{i}^{2}
\end{gathered}
$$

式中, $S$ 为种类数, $N$ 为总尾数, $P_{i}$ 为第 $i$ 种鱼类所占的比例. 所有数据分析在 Excel 2013 软件中完成.

此外, 采用 Gleason 丰富度指数 $D_{\mathrm{GL}}=S / \ln A$, 以计算黄河流域代表性支流的鱼类丰富度,其中 $S$ 表示河 流区段内全部鱼类种类数, $A$ 表示河流区段流域面积 ${ }^{[18]}$.

1.3.2 群落优势种分析 采用百分比相对重要性指数 $(I R I)$ 衡量不同物种的优势度, 公式为:

$$
I R I=\left(\frac{\left(W_{i}+N_{i}\right) \cdot F_{i}}{\sum_{i=1}^{n}\left(W_{i}+N_{i}\right) \cdot F_{i}}\right) \times 100
$$

式中, $W_{i}$ 为第 $i$ 种在渔获物中的重量百分比; $N_{i}$ 为第 $i$ 种在渔获物中的尾数百分比; $F_{i}$ 为监测河段第 $i$ 种的出 现频率.

1.3.3 丰度/生物量比较曲线 采用丰度/生物量比较曲线 (Abundance-Biomass Comparison Curve, 简称 ABC 曲线) 对鱼类群落结构受外界干扰情况进行评价. 丰度/生物量比较曲线方法是在同一坐标系中比较生物量 优势度曲线和数量优势度曲线, 通过两条曲线的分布情况来分析群落在不同干扰程度下的响应. $\mathrm{ABC}$ 曲线 的统计量用 $W$ 表示. 


$$
W=\sum_{i=1}^{S} \frac{\left(W_{i}-N_{i}\right)}{50(S-1)}
$$

式中, $S$ 为出现的物种数. 对未受干扰 (稳定的) 群落, 生物量优势度曲线在数量优势度曲线之上, $W$ 为正值; 在中度干扰状态, 两条曲线出现相交, $W$ 在 0 值附近; 如果数量优势度曲线在生物量优势度曲线之上, $W$ 为 负值,表明群落处于严重干扰状态. ABC 曲线采用 Primer 5.0 软件包完成 ${ }^{[19-21]}$.

1.3.4 群落结构变化与环境因子的关系 采用对应分析探讨鱼类群落结构与环境因子之间的关系. 首先对 物种数据 (尾数百分比) 进行除趋势对应分析 (Detrended Correspondence Analysis, DCA), 以判断后续分析模 型 (线性或单峰) 的选取 (第一轴长 $>4$, 采用单峰模型, 使用典范对应分析 (Canonical Correlation Analysis, $\mathrm{CCA}$ ); 第一轴长 $<3$, 采用线性模型, 使用圥余分析 (Redundancy Analysis, RDA); $3<$ 第一轴长 $<4$, 单峰模型和 线性模型均可). 为了优化分析, 对环境数据进行 $\lg (x+1)$ 转化, 剔除波动因子 (Inflation factor) $>20$ 的环境 因子, 并在分析中降低稀有种的权重. 利用 Monte Carlo 检验 (Monte Carlo test, 999 permutations, $P<0.05$ ) 笁选 出具有重要且独立作用的最少变量组合. 该最少变量组合用于最终的排序分析中. 数据分析和排序图输出 均采用 CANOCO 4.5 软件 ${ }^{[22]}$.

\section{2 结果}

\section{1 水质理化指标}

理化指标检测结果表明伊洛河中下游 5 个河段的环境差异较大 (表 1 ). 凌波大桥、西草甸河段的流量、 $\mathrm{NH}_{3}-\mathrm{N}$ 和 TP 浓度显著低于七里铺河段, 凌波大桥河段的流量、 $\mathrm{NH}_{3}-\mathrm{N}$ 和 $\mathrm{COD}_{\mathrm{Mn}}$ 浓度显著低于黑石关河段 (Kruskal-Wallis 检验, $P<0.05$ ). 依据《地表水环境质量标准》中的 III 类标准, 七里铺河段 $2 、 4 、 6$ 和 8 月调查 期间 $\mathrm{NH}_{3}-\mathrm{N}$ 浓度偏高, 浓度范围为 $1.03 \sim 1.47 \mathrm{mg} / \mathrm{L}$, 水质为 IV 类; 黑石关 2 月调查期间 TP 浓度偏高, 为 0.25 $\mathrm{mg} / \mathrm{L}$, 水质为 $\mathrm{IV}$ 类; 白马寺 4 月 $\mathrm{BOD}_{5}$ 偏高, 为 $5.6 \mathrm{mg} / \mathrm{L}$, 水质为 $\mathrm{IV}$ 类. 七里铺、黑石关和白马寺河段其余监测 期间水质均为 III 类; 凌波大桥、西草甸河段监测期间水质均为 II 类.

表 12016 年伊洛河中下游监测河段水质理化指标

Tab.1 Physico-chemical parameters of water in the middle and lower reaches of the Yiluo River in 2016

\begin{tabular}{|c|c|c|c|c|c|c|c|}
\hline 河段 & 水温 $/{ }^{\circ} \mathrm{C}$ & 流量/ $\mathrm{m}^{3}$ & $\mathrm{pH}$ & $\begin{array}{l}\mathrm{NH}_{3}-\mathrm{N} / \\
(\mathrm{mg} / \mathrm{L})\end{array}$ & $\begin{array}{c}\mathrm{TP} / \\
(\mathrm{mg} / \mathrm{L})\end{array}$ & $\begin{array}{l}\mathrm{BOD}_{5} / \\
(\mathrm{mg} / \mathrm{L})\end{array}$ & $\begin{array}{l}\mathrm{COD}_{\mathrm{Mn}} / \\
(\mathrm{mg} / \mathrm{L})\end{array}$ \\
\hline \multirow[t]{2}{*}{ 七里铺 } & $16.9 \pm 11.4$ & $40.3 \pm 33.1^{\mathrm{a}}$ & $8.0 \pm 0.2$ & $1.1 \pm 0.2^{\mathrm{a}}$ & $0.17 \pm 0.07^{\mathrm{a}}$ & $2.3 \pm 1.0$ & $2.9 \pm 1.5^{\mathrm{ab}}$ \\
\hline & $1.5 \sim 30.0$ & $8.0 \sim 100.0$ & $7.7 \sim 8.2$ & $0.94 \sim 1.47$ & $0.11 \sim 0.28$ & $1.2 \sim 3.5$ & $1.6 \sim 5.5$ \\
\hline \multirow[t]{2}{*}{ 黑石关 } & $20.3 \pm 9.6$ & $37.0 \pm 16.8^{\mathrm{a}}$ & $7.9 \pm 0.1$ & $0.9 \pm 0.1^{\mathrm{a}}$ & $0.11 \pm 0.02^{\mathrm{ac}}$ & $2.6 \pm 0.7$ & $2.8 \pm 0.5^{\mathrm{a}}$ \\
\hline & $1.8 \sim 29.8$ & $12.8 \sim 57.6$ & $7.7 \sim 8.3$ & $0.80 \sim 0.99$ & $0.09 \sim 0.25$ & $1.6 \sim 3.8$ & $2.3 \sim 5.9$ \\
\hline \multirow[t]{2}{*}{ 白马寺 } & $17.1 \pm 11.3$ & $27.7 \pm 15.9^{\mathrm{ab}}$ & $7.8 \pm 0.3$ & $0.6 \pm 0.1^{\mathrm{ab}}$ & $0.14 \pm 0.04^{\mathrm{ac}}$ & $2.8 \pm 1.6$ & $4.1 \pm 1.5^{\mathrm{a}}$ \\
\hline & $1.6 \sim 29.4$ & $7.3 \sim 52.1$ & $7.6 \sim 8.3$ & $0.45 \sim 0.86$ & $0.09 \sim 0.19$ & $1.5 \sim 5.6$ & $2.0 \sim 5.8$ \\
\hline \multirow[t]{2}{*}{ 凌波大桥 } & $17.3 \pm 11.2$ & $17.0 \pm 11.8^{\mathrm{b}}$ & $8.1 \pm 0.1$ & $0.3 \pm 0.1^{\mathrm{b}}$ & $0.06 \pm 0.01^{c}$ & $1.6 \pm 0.8$ & $1.8 \pm 0.3^{b}$ \\
\hline & $1.1 \sim 29.5$ & $5.8 \sim 39.0$ & $7.8 \sim 8.2$ & $0.16 \sim 0.44$ & $0.04 \sim 0.07$ & $1.1 \sim 3.1$ & $1.5 \sim 2.2$ \\
\hline \multirow[t]{2}{*}{ 西草甸 } & $17.0 \pm 11.2$ & $8.3 \pm 3.8^{b}$ & $8.1 \pm 0.1$ & $0.2 \pm 0.1^{\mathrm{b}}$ & $0.05 \pm 0.01^{\mathrm{c}}$ & $1.8 \pm 0.9$ & $2.3 \pm 0.6^{\mathrm{ab}}$ \\
\hline & $2.2 \sim 29.7$ & $4.2 \sim 14.1$ & $8.0 \sim 8.3$ & $0.07 \sim 0.27$ & $0.04 \sim 0.07$ & $1.2 \sim 3.6$ & $1.8 \sim 3.4$ \\
\hline
\end{tabular}

表中同列上标不同小写字母表示有显著差异性 $(P<0.05)$.

\section{2 鱼类组成及多样性}

2016 年在伊洛河中下游 5 个河段共统计鱼类 $214.7 \mathrm{~kg}, 12361$ 尾,共 43 种,隶属于 4 目 9 科 37 属 (附录 I ). 其中, 鲤形目鱼类 31 种, 种类数最多, 占 $72.1 \%$; 其次是鲇形目, 6 种, 占 $14.0 \%$; 鲇形目有 5 种, 占 $11.6 \%$; 胡瓜鱼目有 1 种, 占 $2.3 \%$. 科级水平上,鲤科种类最多, 有 28 种, 占 $65.1 \%$; 魭科次之, 有 4 种, 占 $9.3 \%$; 再次为鳅科 3 种, 占 $7.0 \%$. 鲇科、虾虎鱼科、塘鳢科、刺鳅科、乌鳢科、银鱼科分别为 2 种、 2 种、1 种、1 种、1 种和 1 种, 分别占总物种数的 $4.7 \% 、 4.7 \% 、 2.3 \% 、 2.3 \% 、 2.3 \%$ 和 $2.3 \%$. 空间上, 伊洛河七里铺、黑石关、 洛河凌波大桥、白马寺以及伊河西草甸河段分别采集到鱼类 33 种、15 种、26 种、24 种和 25 种. 
所监测的 5 个伊洛河中下游河段鱼类群落的 Shannon-Wiener 多样性指数的变动范围为 $1.74 \sim 2.45$; Pielou 均匀度指数的变动范围为 $0.59 \sim 0.77$; Margalef 丰富度指数的变动范围为 $2.44 \sim 3.74$; Simpson 优势度 指数的变动范围为 $0.73 \sim 0.87$. 空间上, 西草甸河段的 Shannon-Wiener 多样性指数和 Pielou 均匀度指数最 高, 凌波大桥次之. 黑石关河段的 Shannon-Wiener 多样性指数、Margalef 丰富度指数以及 Simpson 优势度指数 在 5 个河段中最低, 分别为 $2.44 、 1.75$ 和 0.73 . 七里铺河段的 Pielou 均匀度指数在 5 个河段中最低, 为 0.59 ( 图 2).

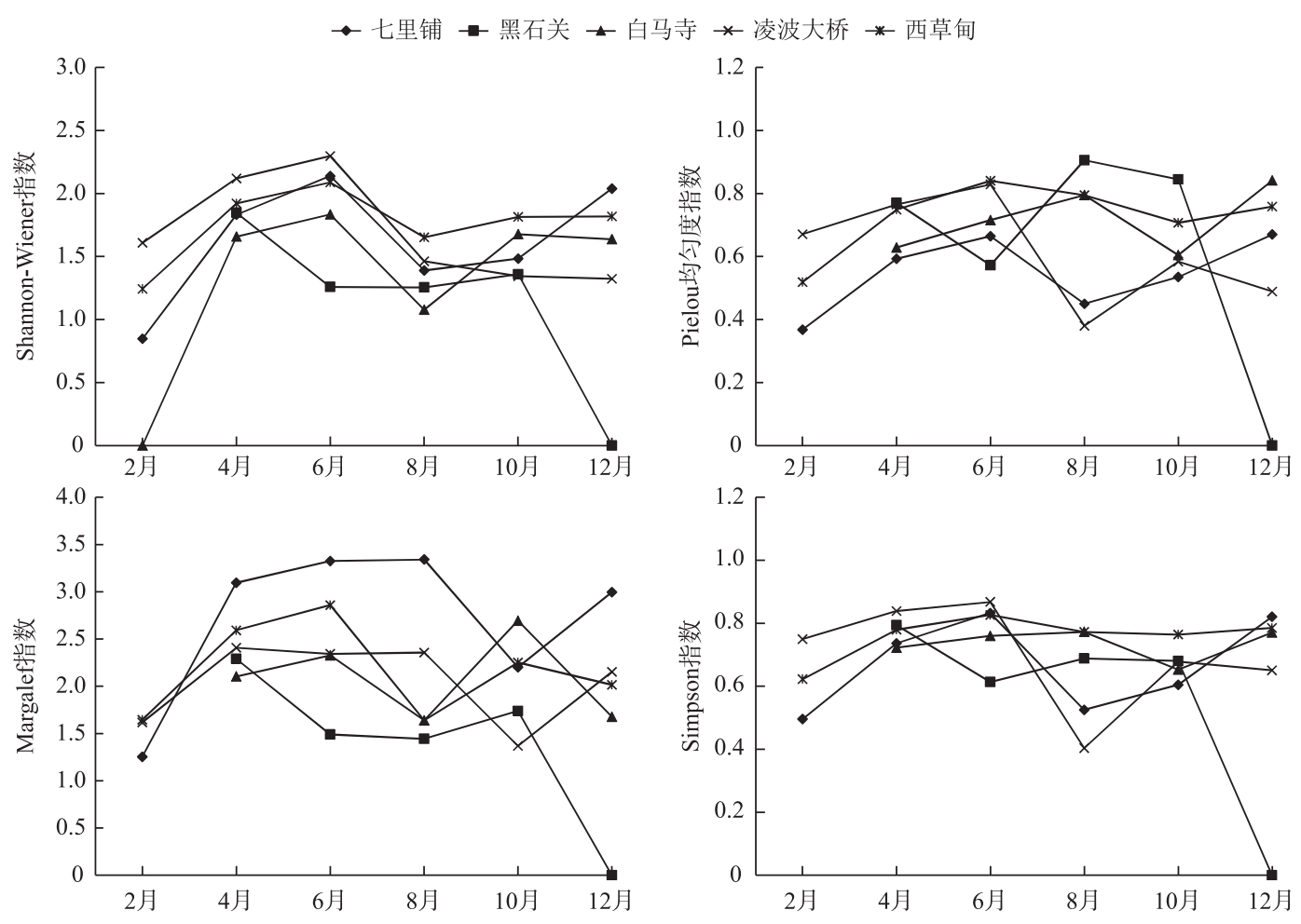

图 2 伊洛河中下游调查河段鱼类多样性指数时空变化

Fig.2 Spatial and temporal variation of fish diversity indexes in the middle and lower reaches of the Yiluo River

\section{3 鱼类群落的优势种}

结果显示, 七里铺河段鲤 (Cyprinus carpio)、粲和似鳊的生物量所占比重最大, 分别为 $26.6 \% 、 23.2 \%$ 和 $14.9 \%$. 粲的数量最多, 占总尾数的 $40.4 \%$. 黑石关河段数量最多的种类为麦穗鱼 (Pseudorasbora parva), 占总 尾数的 $46.7 \%$. 白马寺河段生物量比重较大的种类主要有似鳊、鲫、花䱻 (Hemibarbus maculatus) 和红鯺原鮊 (Cultrichthys erythropterus), 分别占总重量的 $25.4 \% 、 15.6 \% 、 14.0 \%$ 和 $11.3 \%$, 数量较多的种类主要有麦穗鱼 和似鳊, 分别占总尾数的 $28.4 \%$ 和 $15.9 \%$. 凌波大桥河段生物量比重较大的种类主要有兴凯鱊和黄颡鱼 (Pelteobagrus fulvidraco), 分别占总重量的 $45.0 \%$ 和 $17.1 \%$, 数量较多的种类主要有兴凯鱊和鳑鲏属鱼类, 分 别占总尾数的 $25.9 \%$ 和 $32.6 \%$. 西草甸河段生物量比重较大的种类主要有鲤和鲫, 分别占总重量的 $48.0 \%$ 和 $34.5 \%$, 数量较多的种类主要有兴凯鱊、中华鳑鲏 (Rhodeus sinensis) 和鲫, 分别占总尾数的 $35.8 \% 、 19.3 \%$ 和 $14.6 \%$ (表 2).

\section{$2.4 \mathrm{ABC}$ 曲线}

$\mathrm{ABC}$ 曲线图显示, 七里铺和黑石关的 $W$ 值均小于 0 , 丰度优势度曲线总体上位于生物量优势度曲线之 上, 且丰度优势度曲线的起点要明显高于生物量优势度曲线的起点, 表明鱼类群落受到严重干扰, 群落中前 几个优势种均以小型鱼类为主, 且第一优势种的个体均重小于鱼类群落的平均体重. 白马寺和凌波大桥的 
表 2 伊洛河中下游调查河段鱼类群落结构

Tab.2 Fish assemblage structure of the sampling sites in the middle and lower reaches of the Yiluo River

\begin{tabular}{|c|c|c|c|c|c|c|}
\hline 河段 & 鱼名 & 重量/g & 尾数 & 重量占比/\% & 尾数占比/\% & $I R I / \%$ \\
\hline \multirow[t]{7}{*}{ 七里铺 } & 粲 & 26931.2 & 2262 & 21.90 & 38.76 & 35.82 \\
\hline & 似鳊 & 17048.2 & 1074 & 13.87 & 18.40 & 15.59 \\
\hline & 鲫 & 18931.4 & 519 & 15.40 & 8.89 & 13.04 \\
\hline & 鲤 & 26896.9 & 78 & 21.87 & 1.34 & 12.46 \\
\hline & 兴凯鱊 & 6141.8 & 665 & 5.00 & 11.39 & 7.04 \\
\hline & 麦穗鱼 & 920.0 & 350 & 0.75 & 6.00 & 3.98 \\
\hline & 棒花鱼 & 1832.0 & 219 & 1.49 & 3.75 & 2.53 \\
\hline \multirow[t]{7}{*}{ 黑石关 } & 麦穗鱼 & 289.6 & 147 & 5.00 & 46.82 & 45.73 \\
\hline & 鲇 & 1637.6 & 3 & 28.25 & 0.96 & 12.89 \\
\hline & 似鳊 & 740.6 & 21 & 12.77 & 6.69 & 11.45 \\
\hline & 鲫 & 927.1 & 30 & 15.99 & 9.55 & 11.27 \\
\hline & 兴凯鱊 & 44.8 & 59 & 0.77 & 18.79 & 5.76 \\
\hline & 粲 & 247.5 & 16 & 4.27 & 5.10 & 5.51 \\
\hline & 鲤 & 950.0 & 4 & 16.39 & 1.27 & 2.60 \\
\hline \multirow[t]{10}{*}{ 白马寺 } & 麦穗鱼 & 477.3 & 133 & 5.95 & 28.60 & 30.76 \\
\hline & 花䱻 & 1469.6 & 13 & 18.32 & 2.80 & 13.16 \\
\hline & 似鳊 & 1789.7 & 68 & 22.31 & 14.62 & 13.15 \\
\hline & 粲 & 588.2 & 32 & 7.33 & 6.88 & 7.59 \\
\hline & 子陵吻虾虎鱼 & 74.0 & 49 & 0.92 & 10.54 & 6.12 \\
\hline & 红鲑原鲌 & 796.8 & 15 & 9.93 & 3.23 & 5.86 \\
\hline & 鲫 & 1100.6 & 9 & 13.72 & 1.94 & 5.57 \\
\hline & 高体鰟鮍 & 42.5 & 32 & 0.53 & 6.88 & 4.62 \\
\hline & 棒花鱼 & 160.8 & 16 & 2.00 & 3.44 & 3.88 \\
\hline & 马口鱼 & 594.4 & 15 & 7.41 & 3.23 & 2.84 \\
\hline \multirow[t]{9}{*}{ 凌波大桥 } & 兴凯鱊 & 9714.6 & 939 & 38.80 & 28.07 & 40.43 \\
\hline & 中华鰟鮍 & 573.7 & 792 & 2.29 & 23.68 & 13.46 \\
\hline & 瓦氏雅罗鱼 & 5941.9 & 21 & 23.73 & 0.63 & 9.47 \\
\hline & 高体鰟鮍 & 417.0 & 392 & 1.67 & 11.72 & 9.25 \\
\hline & 黄颡鱼 & 3440.3 & 146 & 13.74 & 4.36 & 6.26 \\
\hline & 棒花鱼 & 332.5 & 330 & 1.33 & 9.87 & 5.80 \\
\hline & 麦穗鱼 & 307.3 & 253 & 1.23 & 7.56 & 4.56 \\
\hline & 鲫 & 937.0 & 46 & 3.74 & 1.38 & 2.87 \\
\hline & 小黄䵢鱼 & 57.1 & 91 & 0.23 & 2.72 & 2.04 \\
\hline \multirow[t]{8}{*}{ 西草甸 } & 兴凯鱊 & 5766.5 & 858 & 10.89 & 35.74 & 33.51 \\
\hline & 鲫 & 18196.1 & 362 & 34.38 & 15.08 & 32.16 \\
\hline & 中华鰟鮍 & 409.7 & 451 & 0.77 & 18.78 & 8.70 \\
\hline & 鲤 & 24816 & 30 & 46.88 & 1.25 & 8.24 \\
\hline & 高体鰟鮍 & 282.7 & 209 & 0.53 & 8.70 & 4.43 \\
\hline & 麦穗鱼 & 261.3 & 126 & 0.49 & 5.25 & 4.13 \\
\hline & 小黄䵢鱼 & 110.9 & 108 & 0.21 & 4.50 & 1.93 \\
\hline & 马口鱼 & 821.1 & 22 & 1.55 & 0.92 & 1.27 \\
\hline
\end{tabular}

$W$ 值大于 0 , 且生物量优势度曲线与丰度优势度曲线相交, 表明鱼类群落受到中度干扰, 河段内鱼类群落逐 渐由一种或者几种个体较小的种类占优势. 西草甸的 $W$ 值大于 0 , 生物量优势度曲线总体上位于丰度优势 度曲线之上, 且生物量优势度曲线的起点高于丰度优势度曲线的起点, 表明鱼类群落结构稳定, 优势种中出 现了较大体型的个体 (图 3). 

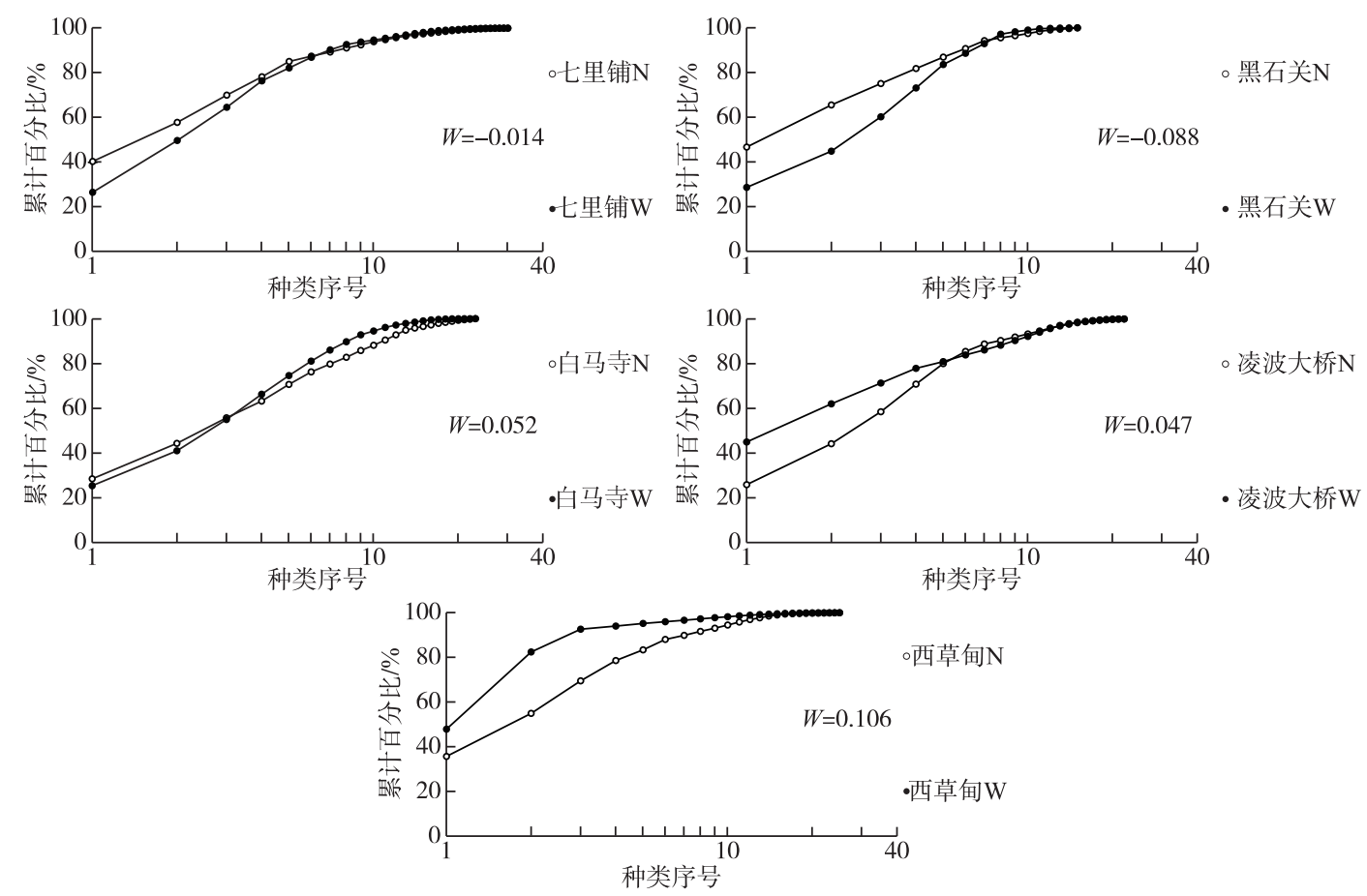

图 3 伊洛河中下游不同河段鱼类群落的 $\mathrm{ABC}$ 曲线 ( $\mathrm{W}$ 为重量百分比, $\mathrm{N}$ 为尾数百分比)

Fig. 3 ABC curves of fish assemblage in the middle and lower reaches of the Yiluo River

表 3 排序轴特征值及其与环境因子的相关系数

Tab.3 Eigenvalues of axes and their correlation coefficients with environmental variables

\begin{tabular}{lcc}
\hline 指标 & 轴 1 & 轴 2 \\
\hline 特征值 & 0.2030 & 0.1200 \\
水温 $(\mathrm{WT})$ & 0.0653 & 0.1632 \\
流量 $(\mathrm{WF})$ & 0.3588 & 0.1741 \\
$\mathrm{pH}$ & -0.4218 & -0.7394 \\
氨氮 $\left(\mathrm{NH}_{3}-\mathrm{N}\right)$ & 0.8922 & -0.009 \\
总磷 $(\mathrm{TP})$ & 0.8493 & -0.0406 \\
五日生化需氧量 $\left(\mathrm{BOD}_{5}\right)$ & 0.3923 & 0.2434 \\
高锰酸盐指数 $\left(\mathrm{COD}_{\mathrm{Mn}}\right)$ & 0.4606 & 0.1869 \\
\hline
\end{tabular}

\section{5 鱼类分布与环境因子的关系}

物种 DCA 结果显示, 4 个排序轴的梯度长度 $(0.595$ 、 $0.339 、 0.220$ 和 0.155 ) 小于 1 , 为线性模型, 故选择冗余 对应分析. 43 个自变量与 7 个环境变量的双序图见图 4.

$\mathrm{RDA}$ 结果显示, $\mathrm{NH}_{3}-\mathrm{N} 、 \mathrm{TP} 、 \mathrm{COD}_{\mathrm{Mn}}$ 环境因子贡献于 轴 $1, \mathrm{pH}$ 、水温等环境因子主要贡献于轴 2 , 轴 1 和轴 2 能 共同解释所有变量的 $77.9 \%$ (图 4). 总体上,沿着轴 1 , 从 左到右,采样点呈现出自上游到下游的空间变化趋势. 随机置换检验发现, $\mathrm{NH}_{3}-\mathrm{N}$ 、TP 和 $\mathrm{pH}$ 是导致伊洛河中下 游鱼类群落结构差异的主要影响因子 $(P<0.05)$ (表 3$)$. 其中, 兴凯鱊、黑鯺鳈 (Sarcocheilichthys nigripinnis)、瓦氏 雅罗鱼 (Leuciscus waleckii) 等种类偏好 $\mathrm{NH}_{3}-\mathrm{N} 、 \mathrm{TP}$ 浓度较 低的河段, 花鲵、马口鱼 (Opsariichthys bidens) 等种类偏好

$\mathrm{pH}$ 相对较低的河段.

\section{3 讨论}

历史资料显示, 伊洛河流域共有鱼类约 50 种 ${ }^{[10]}$. 本研究通过近一年的采样调查, 仅伊洛河中下游就分 布有鱼类 43 种, 多于徐帅等 ${ }^{[10]}$ 报道的 26 种, 增加记录的鱼类主要有清徐胡鮈、鳙、似鮈、黄颖鱼属及鱊亚科 种类. 在流域尺度上, 与黄河其他主要支流相比 ${ }^{[23-27]}$, 伊洛河中下游鱼类丰富度指数达 4.45 , 居黄河主要支 流之首 (表 4). 可见,伊洛河对于维持黄河流域鱼类多样性具有十分重要的作用.

然而, 调查河段鱼类群落结构及其多样性在时空上仍有一定的差异. 历史上, 伊洛河人黄口是黄河鲤天 


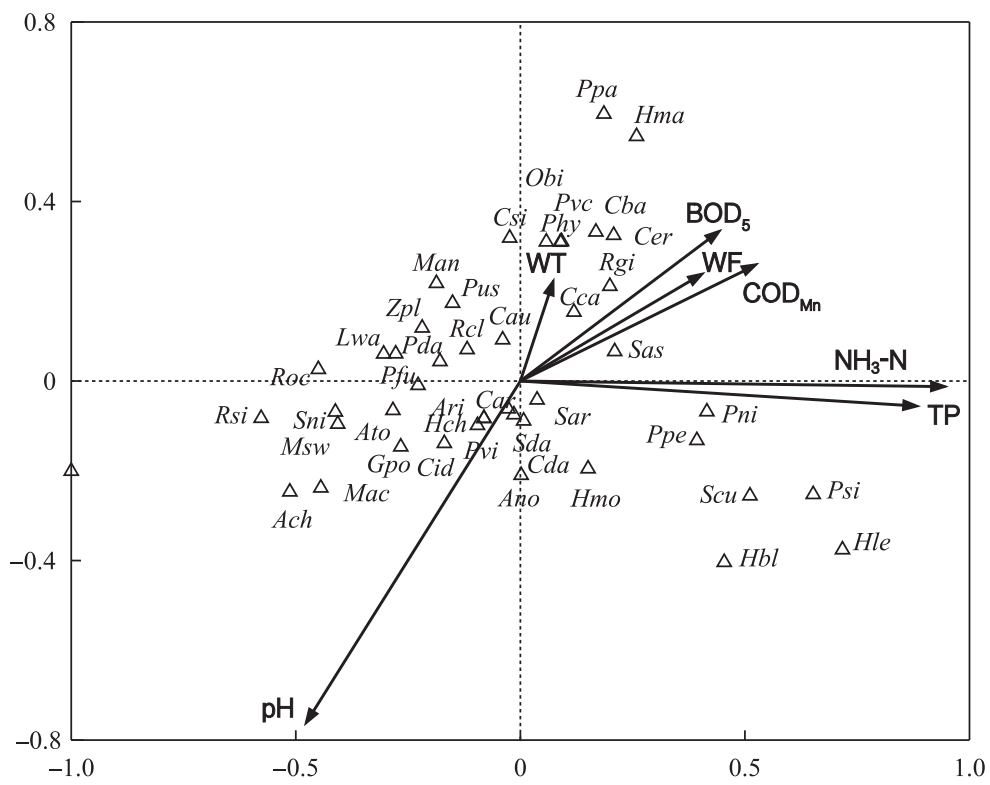

图 4 伊洛河中下游鱼类群落与环境因子间的冗余对应关系(物种缩写详见附录 I )

Fig.4 The redundant correspondence between the fish assemblages and the environmental variables in the middle and lower reaches of the Yiluo River(Abbreviations of fish species are given in Appendix I )

然的产卵场, 河水清澈, 水草茂盛 ${ }^{[6]}$. 但是本研究 调查显示, 七里铺河段鲤的比重不大, 重量百分 比和尾数百分比仅为总重量和总数量的 $21.87 \%$ 和 $1.34 \%$. 粲和似鳊为渔获物的优势物种. 而且 近河口的黑石关河段鱼类物种丰度在各河段中 最低, 仅采集到鱼类 15 种. 伊河魴在本次调查中 没有采集到. $\mathrm{ABC}$ 曲线显示, 七里铺和黑石关河 段鱼类群落处于严重干扰状态, 渔获物以小型鱼 类为主, 其生态习性多为广适性、耐污性种类; 大 规格种类主要为鲢、鳙、草鱼或鲤,量少且多为水 域增殖放流对象. 凌波大桥和西草甸河段水质环 境相对较好, 偏好清洁水体的宽鯺鱲、瓦氏雅罗 鱼、多纹领须鮈 (Gnathopogon polytaenia) 等种类 在该河段也有分布,故这两个河段的鱼类群落结构相对稳定 ( $W$ 值大于 0$)$. 但同历史资料相比 ${ }^{[10]}$, 本研究显 示伊洛河中下游鱼类资源整体上向物种资源量降低、个体小型化等变化趋势. 从物种的环境指示功能看, 上 述变化也反映了伊洛河中下游河流生态环境的退化.

鱼类多样性不仅受捕食、竞争等生物因素的影响,还受生境类型、水温、水质、水利工程等非生物因素的 影响 ${ }^{[28-31]}$. 生境异质性高的河段, 底质、水文等环境条件多样, 能够维持较高的生物多样性 ${ }^{[32-33]}$. 本研究区域 是伊洛河流域的经济重心所在, 区域内的景观格局已发生较大变化 ${ }^{[8,10]}$. 从生境多样性上看, 白马寺、黑石 关河段水流较缓, 生境类型相对单一, 以淤泥、泥沙底质为主; 而凌波大桥和西草甸河段流速相对较高, 且河 道宽窄相间,有心滩分布, 底质除泥沙底质外,也分布有砾石滩,生境异质性相对较高,故这两个河段的鱼类 多样性水平较高. 此外, 研究结果显示, 水质污染也是影响伊洛河鱼类多样性的重要因素. 2016 年七里铺、黑 石关及白马寺河段多次出现水质不达 III 类水, 超标因子以氨氮、总磷和 $\mathrm{BOD}_{5}$ 为主. 历史资料显示, 2011 年伊 
洛河流域内 $47.7 \%$ 的水环境功能区水质不达标, 超标河段主要分布在洛河宜阳以下的洛阳、偃师等河段 ${ }^{[10]}$. 污染原因主要是排污企业超标排放, 生活污水未得到有效集中处理 ${ }^{[6,34]}$. 河流氮磷等污染加重, 除影响鱼 类、底栖动物正常的生理、生长外, 还会促使水体藻类及其他微生物大量繁殖, 溶解氧浓度减少, 水体通气 差, 导致底栖性鱼类减少, 水域鱼类群落结构单一. 结合其他研究结果, 分析导致伊洛河中下游鱼类多样性 下降的其他因素包括: (1) 水利工程建设导致的河流连通性降低, 土著鱼类适宜的栖息地减少. 目前, 伊洛河 干流已建、在建水电站 40 余座. 密集的水电站建设, 导致河流纵向连通性丧失, 枯水期及平水期多个河段存 在断流、脱流现象. 此外,无序的采石、挖砂造成河道下切或沿岸砂石堆积, 阻隔了主河道与漫滩之间的水文 连通, 导致河道与河岸带生境的横向连通性丧失, 进而使得鱼类栖息地减少 ${ }^{[35-37]}$. (2) 非法渔具的使用. 随着 沿岸地区居民生活水平的提高, 人们对土著野生鱼类的需求日益增加, 导致了滥捕行为的蔓延. 调查期间, 研究人员发现电捕、毒鱼等非法捕捞活动时有发生. 这些人为因素也加剧了鱼类资源的衰退.

群落生态学理论认为, 河流环境的变化对鱼类多样性影响的驱动机制不仅表现在群落结构上, 如物种 组成、个体丰度的变化,还表现为群落功能的同质化 ${ }^{[38-39]}$. 本研究中, 尽管在七里铺河段采集到的鱼类种类 最多, 但其均匀度指数最低, 其原因在于该河段鱼类群落结构组成不均, 资源量主要集中在少数几个优势物 种上, 如粲、似鳊、鲫等. 同时在群落功能上, 这些种类属于广适性、耐污性鱼类. 随着河流环境的退化, 这些 种类取代了原有的亲流性土著鱼类 (瓦氏雅罗鱼、多纹领须鮈等) 成为调查河段的优势种. 当然,伊洛河流域 不同尺度环境因子对鱼类群落和功能多样性的影响机制仍有待深人研究.

总体来说,伊洛河中下游鱼类多样性现状是水质污染、河流连通性降低、适宜栖息地减少、非法捕捞等 多因素综合作用的结果. 为积极推进流域水生态文明建设, 针对伊洛河鱼类多样性现状, 建议采取以下措 施: (1) 全面开展伊洛河流域水生生物多样性监测, 加强稀有物种 (如伊河鲂) 的就地和迁地保护; (2) 应重 视洛阳河段的水质污染, 加强流域内水质监管与治理; 科学开展流域小水电的回顾性评估, 合理恢复河流连 通性; (3) 在橡胶坝下游减水河段以及受损的鱼类产卵场等重点区域, 开展生态修复, 科学实施伊洛河梯级 橡胶坝群的联合调度运行; (4) 加强黄河郑州段黄河鲤国家级水产种质资源保护区伊洛河核心区 (伊洛河巩 义市康店大桥至伊洛河人黄河口处) 和洛河鲤国家级水产种质资源保护区的管理,积极推进保护区全面 禁渔.

\section{4 附录}

附录 I 见电子版( DOI: 10.18307/2019.0217).

\section{5 参考文献}

[ 1 ] Fu BJ, Yu DD, Lv N. An indicator system for biodiversity and ecosystem services evaluation in China. Acta Ecologica Sini$c a, 2017,37$ (2) : 341-348. [傅伯杰, 于丹丹, 吕楠. 中国生物多样性与生态系统服务评估指标体系. 生态学报, $2017,37(2): 341-348$. ]

[ 2 ] Hermoso V. Freshwater ecosystems could become the biggest losers of the Paris Agreement. Global Change Biology, 2017, 23: 3433-3436.

[ 3 ] Strayer DL, Dudgeon D. Freshwater biodiversity conservation: recent progress and future challenges. Journal of the North American Benthological Society, 2010, 29(29) : 344-358.

[ 4 ] Karr JR. Ecological health indicators. In: Jorgensen SE, Fath B eds. Encyclopedia of ecology. Oxford: Academic Press, 2008: 1037-1041.

[ 5 ] Chen J, Guo YL, Lu XL et al. Species diversity of herbaceous communities in the Yiluo River Basin. Acta Ecologica Sini$c a, 2012,32(10): 3021-3030$. [陈杰, 郭屹立, 卢训令等. 伊洛河流域草本植物群落物种多样性. 生态学报, 2012, 32(10) : 3021-3030.]

[ 6 ] Yang XB, Jiao YH, Xia J et al. Evaluation of fishery water quality of the spawning ground of Cyprinus carpio haematoperus in Yiluo River. Journal of Hydroecology, 2011, 32(4): 42-45. [杨雪冰, 焦宇卉, 夏杰等. 伊洛河黄河鲤天然产卵场 渔业水质评价. 水生态学杂志, $2011,32(4)$ : 42-45.]

[ 7 ] Li TH, Huang XL, Jiang XH et al. Assessment of ecosystem health of the Yellow River with fish index of biotic integrity. 
Hydrobiologia, 2015, 412(28) : 1-13.

[ 8 ] Wang B, Zang L. A study on the development strategy of Yiluo River Basin. Areal Research and Development, 2007, 26 (6) : 53-56. [王兵, 藏玲. 伊洛河流域开发战略研究. 地域研究与开发, 2007, 26(6) : 53-56.]

[ 9 ] Huang P, Ye YZ, Gao HM et al. Biodiversity investigation and assessment of Yihe-Luohe River Basin in Henan Province. Journal of Henan Normal University: Natural Science Edition, 2012, 40(1) : 142-145. [黄萍, 叶永忠, 高红梅等. 河南 省伊洛河流域生物多样性调查及评价. 河南师范大学学报：自然科学版, 2012, 40(1) : 142-145.]

[10] Xu S, Gao TL, Ge L. The water ecological status and protection countermeasures of Yihe-Luohe River Basin. Journal of Henan Science and Technology, 2014, (16) : 184-186. [徐帅, 高天立, 葛雷. 伊洛河流域水生态现状及保护对策. 河南科技, 2014, (16): 184-186.]

[11] Zhu SQ ed. Synopsis of freshwater fishes of China. Nanjing: Jiangsu Science and Technology Publishing House, 1995: 549. [ 朱松泉. 中国淡水鱼类检索. 南京: 江苏科学技术出版社, 1995: 549.]

[12] Chen YY ed. Fauna Sinica (Osteichthyes) : Cypriniformes II . Beijing: Science Press, 1998. [ 陈宜瑜. 中国动物志 - 硬 骨鱼纲・鲤形目 (中卷). 北京: 科学出版社, 1998.]

[13] Yue PQ ed. Fauna Sinica (Osteichthyes) : Cypriniformes III. Beijing: Science Press, 2000. [乐佩琦. 中国动物志 - 硬 骨鱼纲・鲤形目 (下卷). 北京: 科学出版社, 2000.]

[14] Li SZ ed. Fishes of the Yellow River and Beyond. Keelung: The Sueichan Press, 2015: 640. [李思忠. 黄河鱼类志:黄 河鱼类专著及鱼类学文选. 基隆: 水产出版社, 2015: 640.]

[15] Ministry of Environmental Protection of the People's Republic of China, Editorial Board of Water and Wastewater Monitoring and Analysis Methods eds. Water and Wastewater Monitoring and Analysis Methods:4th edition. Beijing: China Environmental Science Press, 2002. [ 国家环境保护总局《水和废水监测分析方法》编委会. 水和废水监测分析方法: 第 4 版. 北京: 中国环境科学出版社, 2002.]

[16] Ludwig JA, Reynolds JF eds. Statistical ecology, a primer on methods and computing. New York: John Wiley and Sons, 1988.

[17] Magurran AE ed. Ecological diversity and its measurement. London: Croom Helm, 1988.

[18] Jiang ZG, Ma KP, Han XG eds. Hangzhou: Zhejiang Science \& Technology Press, 1997. [蒋志刚, 马克平, 韩兴国. 保 护生物学. 杭州: 浙江科技出版社, 1997.]

[19] Clarke KR, Warwick RM. Change in marine communities: an approach to statistical analysis and interpretation. Plymouth: PRIMPER-E, 2001.

[20] Warwick RM. A new method for detecting pollution effects on marine macrobenthic communities. Marine Biology, 1986, 92(4): 557-562.

[21] Ren P, Fang PF, Bao YX et al. Variation in macrobenthic community characteristics among different types of wetlands in Xuanmen Bay. Acta Ecologica Sinica, 2016, 36(18) : 5632-5645. [任鹏, 方平福, 鲍毅新等. 漩门湾不同类型湿地大 型底栖动物群落特征比较研究. 生态学报, 2016, 36(18) : 5632-5645.]

[22] ter Braak CJF, Smilauer P. CANOCO Reference Manual and CanoDraw for Windows User's Guide: Software for Canonical Community Ordination (version 4.5). Ithaca, NY, USA: Microcomputer Power, 2002.

[23] Tang WJ, Chen YF, Ding CZ. The current situation and protection of fish resources in Huangshui River in Qinghai Province. Journal of Dalian Ocean University, 2013, 28(3) : 307-313. [ 唐文家, 陈毅峰, 丁城志. 青海省湟水鱼类资源现 状及保护对策. 大连海洋大学学报, 2013, 28(3): 307-313.]

[24] Zhang H, Wang GM. Management situation and countermeasures on wetland in Wuding River of Shaanxi Province. Journal of Shaanxi Normal University: Natural Science Edition, 2007, (s1) : 197-200. [张浩, 王根民. 陕西省无定河湿地管理 现状与对策. 陕西师范大学学报: 自科版, 2007, (s1) : 197-200.]

[25] Li WH, Zhao RL. Analysis of Fenhe River fishery resource status. Shanxi Water Resources, 2015, (5): 31-32. [李文华, 赵瑞亮. 汾河渔业资源现状及分析. 山西水利, 2015, (5) : 31-32.]

[26] Wu W, Xu ZX, Yin XW et al. Fish community structure and biological integrity in the Wei River basin. Research of Environmental Sciences, 2014, 27(9): 981-989. [武玮, 徐宗学, 殷旭旺等. 渭河流域鱼类群落结构特征及其完整性评 价. 环境科学研究, 2014, 27(9): 981-989.]

[27] Zhu GQ, Zhao RL, Hu ZP et al. Fish distribution and species diversity in major rivers in Shanxi Province. Chinese Journal of Fisheries, 2014, 27(2): 38-45. [ 朱国清, 赵瑞亮, 胡振平等. 山西省主要河流鱼类分布及物种多样性分析. 水 
产学杂志, 2014, 27(2) : 38-45.]

[28] Dudgeon D, Arthington AH, Gessner MO et al. Freshwater biodiversity: importance, threats, status and conservation challenges. Biological Reviews, 2006, 81(2) :163-182.

[29] Cazzolla GR. Freshwater biodiversity: a review of local and global threats.International Journal of Environmental Studies, 2016, 73(6) : 887-904.

[30] Huang L, Li J eds. Status of freshwater fish biodiversity in the Yangtze River Basin, China. In: Nakano S, Yahara T, Nakashizuka T eds. Aquatic Biodiversity Conservation and Ecosystem Services. Singapore: Springer, 2016: 13-30.

[31] Chea R, Lek S, Ngor P et al. Large-scale patterns of fish diversity and assemblage structure in the longest tropical river in Asia. Ecology of Freshwater Fish, 2017, 26(4) : 575-585.

[32] Willis SC, Winemiller KO, Lopez-Fernandez H. Habitat structural complexity and morphological diversity of fish assemblages in a Neotropical floodplain river. Oecologia, 2005, 142(2) : 284-295.

[33] Pander J, Mueller M, Geist J. Habitat diversity and connectivity govern the conservation value of restored aquatic floodplain habitats. Biological Conservation, 2018, 217: 1-10.

[34] Zhang SK, Cheng WX, Xu XL et al. Analysis of water pollution causes and prevention and control measures in Yiluo River water quality. Yellow River, 2014, 36(7): 76-79. [张世坤, 程卫习, 徐晓琳等. 伊洛河水污染现状成因分析及防治 对策. 人民黄河, 2014, 36(7): 76-79.]

[35] The Yellow River Water Resources Protection Science Research Institute. Environmental impact report for the comprehensive planning of the Yihe-Luohe River Basin, 2014. [黄河水资源保护科学研究院. 伊洛河流域综合规划环 境影响报告书, 2014.]

[36] Shrestha S, Farrelly J, Eggleton M et al. Effects of conservation wetlands on stream habitat, water quality and fish communities in agricultural watersheds of the lower Mississippi River Basin. Ecological Engineering, 2017, 107 : 99-109.

[37] Ding Y, Wu Z, Zhu Z et al. Species composition, trend of biodiversity variation and conservation of the fish in Lijiang River (in China). Environmental Biology of Fishes, 2018, 101(5): 675-685.

[38] Villéger S, Grenouillet G, Brosse S. Functional homogenization exceeds taxonomic homogenization among European fish assemblages. Global Ecology and Biogeography, 2015, 23(12) : 1450-1460. DOI: 10.1111/geb.12226.

[39] Su GH, Xu J, Akasaka Met al. Human impacts on functional and taxonomic homogenization of plateau fish assemblages in Yunnan, China. Global Ecology and Conservation, 2015, 4(Supplement C) : 470-478. 
附录 I 伊洛河中下游调查河段鱼类组成

Appendix I Fish species collected in in the middle and lower reaches of the Yiluo River

\begin{tabular}{|c|c|c|c|c|c|c|c|c|c|}
\hline 目 & 科 & 鱼名 & 拉丁名 & 缩写 & 七里铺 & 黑石关 & 白马寺 & 凌波大桥 & 西草甸 \\
\hline 胡瓜鱼目 Osmeridae & 银鱼科 Salangidae & 大银鱼 & Protosalanx hyalocranius & Phy & + & & + & + & \\
\hline \multirow[t]{28}{*}{ 鲤形目 Cypriniformes } & 鲤科 Cyprinidae & 马口鱼 & Opsariichthys bidens Günther & $O b i$ & + & + & + & + & + \\
\hline & & 宽鯺鱲 & Zacco platypus & $Z p l$ & & & & & + \\
\hline & & 瓦氏雅罗鱼 & Leuciscus waleckii( (Dybowskii) & $L w a$ & & & & + & \\
\hline & & 赤眼䲡 & Squaliobarbus curriculus( Richardson) & $S c u$ & + & & & & \\
\hline & & 草鱼 & Ctenopharyngodon idellus & Cid & + & & & + & \\
\hline & & 粲 & Hemiculter leucisculus( Basilewsky) & Hle & + & + & + & + & + \\
\hline & & 贝氏粲 & Hemiculter bleekeri Warpachowski & $H b l$ & + & & & & + \\
\hline & & 达氏鮊 & Culter dabryi & $C d a$ & + & & + & & \\
\hline & & 红鯺原鲌 & Cultrichthys erythropterus (Basilewsky) & Cer & + & & + & & \\
\hline & & 鳊 & Parabramis pekinensis (Basilewsky) & Ppe & + & & & & \\
\hline & & 似鳊 & Pseudobrama simoni( Bleeker) & $P s i$ & + & + & + & & \\
\hline & & 鲢 & Hypophthalmichthys molitrix (Cuvier et Valenciennes) & Нто & + & & & & \\
\hline & & 鳙 & Aristichthys nobilis & Ano & + & & & & + \\
\hline & & 花 & Hemibarbus maculatusBleeker & Hта & + & + & + & & + \\
\hline & & 麦穗鱼 & Pseudorasbora parva( Temminck et Schlegel) & $P p a$ & + & + & + & + & + \\
\hline & & 黑鯺鳈 & Sarcocheilichthys nigripinnis( Günther) & Sni & + & & & + & + \\
\hline & & 银鮈 & Squalidus argentatus (Sauvage et Dabry) & Sar & + & + & + & + & \\
\hline & & 多纹领须鮈 & Gnathopogon polytaenia & Gpo & & & & + & + \\
\hline & & 清徐胡鮈 & Huigobio chinssuensis & $H c h$ & & & & + & \\
\hline & & 棒花鱼 & Abbottina rivularis (Basilewsky) & Ari & + & & + & + & + \\
\hline & & 似鮈 & Pseudogobio vaillanti & $P v i$ & & & & + & \\
\hline & & 蛇鮈 & Saurogobio dabryi Bleeker & $S d a$ & + & & + & + & + \\
\hline & & 中华鳑鲏 & Rhodeus sinensis Günther & $R s i$ & + & & + & + & + \\
\hline & & 高体鳑鲏 & Rhodeus ocellatus( Kner) & Roc & + & + & + & + & + \\
\hline & & 兴凯鱊 & Acheilognathus chankaensis (Dybowski) & Ach & + & + & + & + & + \\
\hline & & 越南鱊 & Acheilognathus tonkinensis & Ato & & & & & + \\
\hline & & 鲤 & Cyprinus carpio Linnaeus & $C c a$ & + & + & + & + & + \\
\hline & & 鲫 & Carassius auratus( Linnaeus) & $\mathrm{Cau}$ & + & + & + & + & + \\
\hline
\end{tabular}




\begin{tabular}{|c|c|c|c|c|c|c|c|c|c|}
\hline 目 & 科 & 鱼名 & 拉丁名 & 缩写 & 七里铺 & 黑石关 & 白马寺 & 凌波大桥 & 西草甸 \\
\hline & 鲉科 Cobitidae & 中华花鳅 & Cobitis sinensis Sauvage et Dabry & $C s i$ & & + & & & + \\
\hline & & 泥鲉 & Misgurnus anguillicaudatus (Cantor) & Man & + & + & & + & + \\
\hline & & 大鳞副泥鳅 & Paramisgurnus dabryanus Sauvage & $P d a$ & + & & & + & \\
\hline \multirow[t]{6}{*}{ 鲇形目 Siluriformes } & 魭科 Bagridae & 黄颡鱼 & Pelteobagrus fulvidraco( Richardson) & $P f u$ & + & & + & + & + \\
\hline & & 瓦氏黄颡鱼 & Pelteobagrus vachelli( Richardson) & $P v c$ & + & & + & & \\
\hline & & 光泽黄颡鱼 & Pelteobagrus nitidus( Sauvage et Dabry) & Pni & + & & + & & \\
\hline & & 乌苏拟鲿 & Pseudobagrus ussuriensis (Dybowski) & Pus & + & & + & + & \\
\hline & 鲇科 Siluridae & 胡子鲇 & Clarius batrachus( Linnaeus) & $C b a$ & & + & & & \\
\hline & & 鲇 & Silurus asotus Linnaeus & Sas & + & + & & + & + \\
\hline \multirow[t]{5}{*}{ 鲇形目 Perciformes } & 塘鳢科 Eleotridae & 小黄黚鱼 & Micropercops swinhonis(Günther) & $M s w$ & & & + & + & + \\
\hline & 虾虎鱼科 Gobiidae & 子陵吻虾虎鱼 & Rhinogobius giurinus ( Rutter) & Rgi & + & + & + & + & + \\
\hline & & 波氏吻虾虎鱼 & Rhinogobius cliffordpopei(Nichols) & Rcl & + & & + & + & + \\
\hline & 刺鳅科 Mastacembelidae & 刺䱊 & Mastacembelus aculeatus & Mac & & & & & + \\
\hline & 乌鳢科 Channidae & 乌鳢 & Channa argus & Car & + & & + & & \\
\hline
\end{tabular}

备注:“+”表示各河段调查期间采集到的种类. 